\title{
Halogen bonding with the halogenabenzene bird structure, halobenzene and halocyclopentadiene
}

\author{
Emma L. Cates and Tanja van Mourik* \\ School of Chemistry, University of St Andrews, North Haugh, St Andrews KY16 9ST (UK) \\ Correspondence to: Tanja van Mourik (E-mail: tanja.vanmourik@st-andrews.ac.uk)

\section{Corresponding Author} \\ Tanja van Mourik \\ University of St Andrews \\ North Haugh \\ St Andrews KY16 9ST \\ United Kingdom \\ Email: tanja.vanmourik@st-andrews.ac.uk \\ Phone: +44 1334463822 \\ ORCID: 0000-0001-7683-3293
}

\begin{abstract}
The ability of the "bird-like" halogenabenzene molecule, referred to as X-bird ( $\mathrm{X}=\mathrm{Cl}$ to At), to form halogen-bonded complexes with the nucleophiles $\mathrm{H}_{2} \mathrm{O}$ and $\mathrm{NH}_{3}$ was investigated using double-hybrid density functional theory and the aug-cc-pVTZ/aug-cc-pVTZ-PP basis set. The structures and interaction energies were compared with 5-halocyclopenta-1,3-diene (halocyclopentadiene; an isomer of halogenabenzene) and halobenzene, also complexed with $\mathrm{H}_{2} \mathrm{O}$ and $\mathrm{NH}_{3}$. The unusual structure of the $\mathrm{X}$ bird, with the halogen bonded to two carbon atoms, results in two distinct $\sigma$-holes, roughly at the extension of the $\mathrm{C}-\mathrm{X}$ bonds. Based on the behaviour of the interaction energy (which increases for heavier halogens) and van der Waals (vdW) ratio (which decreases for heavier halogens), it is concluded that the X-bird forms proper halogen bonds with $\mathrm{H}_{2} \mathrm{O}$ and $\mathrm{NH}_{3}$. The interaction energies are larger than those of the halogen-bonded complexes involving halobenzene and halocyclopentadiene, presumably due to the presence of a secondary interaction.
\end{abstract}

\section{Introduction}

Halogen-substituted benzenes have received ample attention in the literature. The most common of these are structures where one or more hydrogens are replaced by halogens $\left(\mathrm{C}_{6} \mathrm{H}_{6-\mathrm{n}} \mathrm{X}_{n} ; \mathrm{X}=\mathrm{F}, \mathrm{Cl}, \mathrm{Br}, \mathrm{I} ; \mathrm{n}=1-6\right){ }^{[1-}$

${ }^{9]}$ In our group, we have recently studied the interaction between singly-substituted halobenzenes (with halogens up to At) and one or two water molecules, in the context of locating possible halogen bonding between the halogen and the water oxygen. ${ }^{[10]}$ Conversely, benzene structures where a carbon is replaced by a halogen have received much less attention so far. Such structures, labelled halogenabenzenes, were first introduced by Glukhovtsev in $1991 .{ }^{[11]}$ Based on semiempirical calculations, he proposed a planar $8 \pi-$ electron system. However with $8 \pi$-electrons, this system is antiaromatic. Based on higher-level DFT and MP2 calculations, Rawashdeh et al. showed in $2017^{[12]}$ that the planar iodabenzene structure (with $C_{2 v}$ constraint) is a transition state with one imaginary frequency; the minima it is connected to are both an identical $\mathrm{C}_{\mathrm{s}}$-symmetric non-planar structure (see Figure 1). Rawashdeh et al. dubbed this structure "bird" because of the similarity with a flying bird (the halogen being the bird's head and the closest hydrogens 
wings stretched upwards). This minimum is by all means not the lowest-energy structure on the $\mathrm{C}_{5} \mathrm{H}_{5} \mathrm{I}$ potential energy surface: a bicyclic structure with one imaginary frequency is $55 \mathrm{kcal} / \mathrm{mol}$ more stable than the bird, whereas the corresponding 5-iodocyclopenta-1,3-diene minimum-energy structure is 73 $\mathrm{kcal} / \mathrm{mol}$ lower than the bird structure, ${ }^{[12]}$ see Figure 1 for their structures. The authors established that there is a $14 \mathrm{kcal} / \mathrm{mol}$ barrier from the bird to the 5-iodocyclopenta-1,3-diene minimum. Whereas the iodabenzene bird structure hypothesised by Rawashdeh et al. may not be experimentally observable, the authors point out that trinitro- and tricyano bird halogenabenzenes (with the $\pi$-acceptor substituents in the ortho and para positions) may be isolable at low temperatures. Very recently, Liu et al. followed up on the paper by Rawashdeh et al. and explored the reasons the symmetry-breaking of the planar $\mathrm{C}_{2 v^{-}}$ symmetric iodabenzene structure to form the $\mathrm{C}_{\mathrm{s}}$-symmetric bird-like structure. They explained the nonplanar bird geometry using Pseudo Jahn-Teller Effect theory combined with ab initio calculations. ${ }^{[13]}$
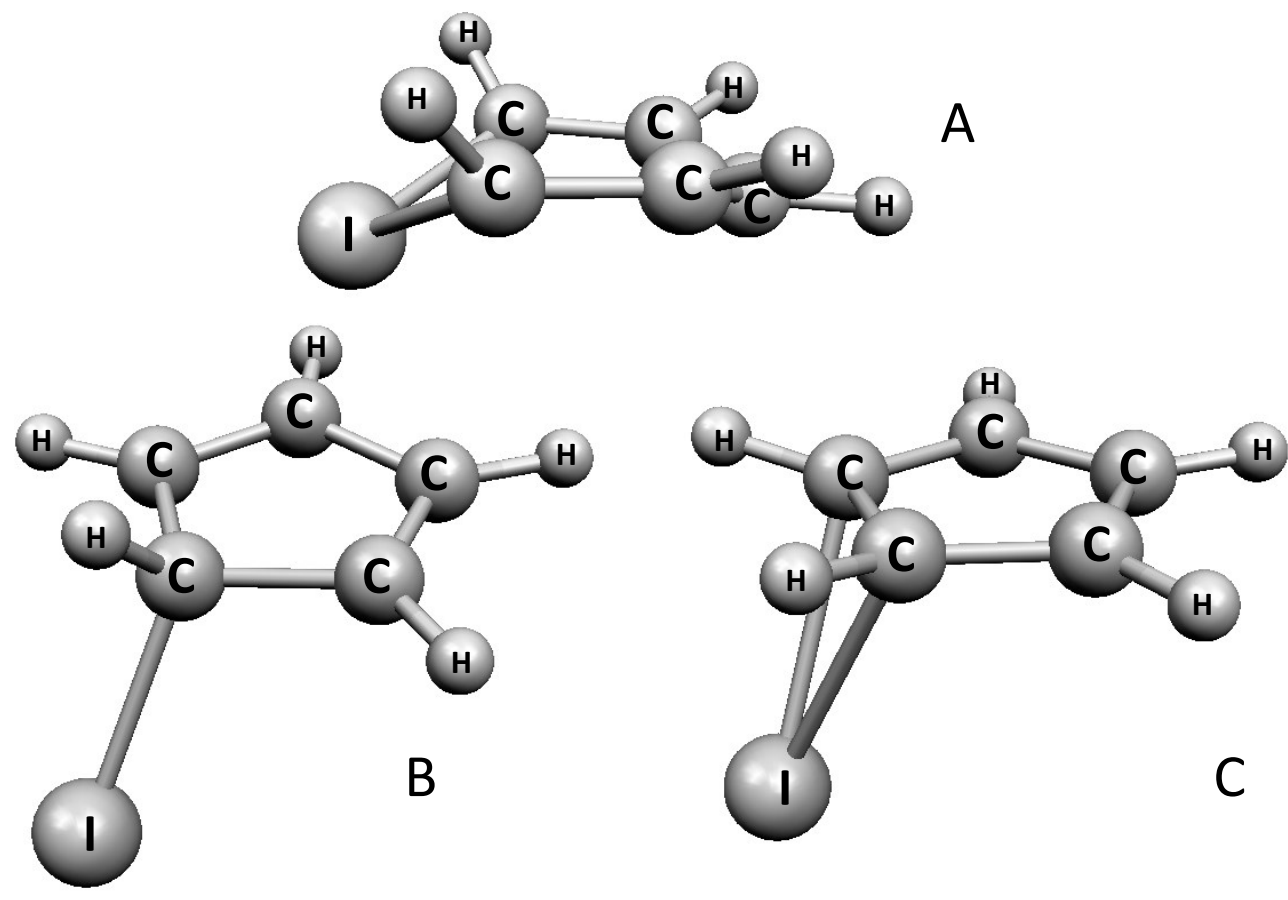

Figure 1. Three stationary points on the $\mathrm{C}_{5} \mathrm{H}_{5}$ l potential energy surface, optimised with mPW2PLYP/augcc-pVTZ(-PP). A. bird-like iodabenzene. B. 5-iodocyclopenta-1,3-diene. C. Bicyclic structure. The bicyclic structure is a transition state, evidenced by the presence of one imaginary frequency. The energies of the bird and bicyclic structures relative to 5-iodocyclopenta-1,3-diene are 305.8 and $75.6 \mathrm{~kJ} / \mathrm{mol}$, respectively.

The bird structure is unusual in the sense that the iodine is bonded to two carbon atoms. With the current interest in halogen bonds (X-bonds) in our group, we wondered how this topology would affect the halogen's ability to form X-bonds. Halogen bonds are the most studied of the collective $\sigma$-hole interactions. In halogen bonds, $\sigma$-holes are electron-deficient regions at the elongation of the R-X bond (where $\mathrm{R}$ is the atom or group the halogen $\mathrm{X}$ is covalently bonded to). Their origin lies in the anisotropy of the electron density around the halogen, with electron density accumulating in a belt orthogonal to the covalent bond, leaving the area opposite the R-X bond (the $\sigma$-hole) depleted of electron density. Would this $\sigma$-hole still exist in the halogenabenzene molecules? In the current paper we explore this question. 
We investigate the halogen-bonding ability of halogenabenzene molecules and contrast these with the more classical halobenzene and 5-halocyclopenta-1,3-diene molecules. As nucleophiles we have chosen $\mathrm{H}_{2} \mathrm{O}$ and $\mathrm{NH}_{3}$. As in previous work we use halogens up to and including astatine, to facilitate establishing trends even in cases where chlorine does not form a X-bond. We did not consider fluorinated structures, as fluorine tends not to form X-bonds. ${ }^{[14]}$

Research into X-bonds has really taken off the last decade and a plethora of research on halogen-bonded systems is available in the literature. We refer here to a number of recent review articles. ${ }^{[15-21]}$ In our group, we have studied the competition between $\mathrm{H}$-bonds and $\mathrm{X}$-bonds in halogenated methyluracil$\left(\mathrm{H}_{2} \mathrm{O}\right)_{n}{ }^{[22-24]}$ and halobenzene- $\left(\mathrm{H}_{2} \mathrm{O}\right)_{n}{ }^{[10]}$ complexes $(n=1,2)$. QTAIM (quantum theory of atoms in molecules) showed that the X-bonds were purely electrostatic in nature. ${ }^{[24]}$ In 2013 Desiraju et al. proposed a definition of the X-bond, listing a number of geometric, spectroscopic and electronic features as indications for a halogen bond $\mathrm{R}-\mathrm{X} \bullet \bullet \mathrm{Y}$ (where $\mathrm{Y}$ is the nucleophile). ${ }^{[25]}$ The geometric features include: (i) the interatomic distance between the halogen and the nucleophile tends to be smaller than the sum of the van der Waals radii. We label this feature the van der Waals ratio (vdW ratio) below, (ii) the R-X bond length is usually shorter than the unbonded $R-X$ bond length and (iii) the $R-X \bullet \bullet \vee Y$ angle is usually close to $180^{\circ}$. Concerning the latter, although generally angles between $160-180^{\circ}$ are classified as indicative of halogen bonding, in previous work we found that significant non-linear X-bonds (angles as small as $150^{\circ}$ ) can form if there are competing interactions. ${ }^{[22]}$ Another halogen-bond feature listed by Desiraju et al. is that the halogen-bond strength decreases as the electronegativity increases i.e. from the heavier towards the lighter halogens. ${ }^{[25]}$ We observed this before, ${ }^{[10,22,23]}$ and changing the nature of the halogen atom (from $\mathrm{Cl}$ to $\mathrm{Br}$ ) was listed as one of the measures to make X-bonds stronger than hydrogen bonds in $\mathrm{H}_{2} \mathrm{C}=\mathrm{S} \bullet \bullet \mathrm{HOX}^{[26]}$ The increasing strength of halogen-bonds involving molecules with the heavier halogens has also previously be linked with the increased $\sigma$-hole for these systems, as visualised using molecular electrostatic potential maps. ${ }^{[15,27-34]}$ We will use these features to evaluate the existence of X-bonds in the complexes studied in this work.

\section{Methodology}

Complexes of $\mathrm{H}_{2} \mathrm{O}$ and $\mathrm{NH}_{3}$ interacting with the bird-like halogenabenzene (hereafter referred to as $\mathrm{X}$ bird), halocyclopenta-1,3-diene (X-cyclopentadiene) and halobenzene structures with $\mathrm{X}=\mathrm{Cl}, \mathrm{Br}$, I and $\mathrm{At}$, were optimised using the mPW2-PLYP double hybrid density functional ${ }^{[35]}$ and the aug-cc-pVTZ basis set $^{[36,37]}$ for all atoms except I and At; For the I and At atoms the aug-cc-pVTZ-PP basis se, ${ }^{[38,39]}$ which includes relativistic effective core potentials, was employed. The interaction energies were corrected for basis set superposition error (BSSE) using Boys and Bernardi's counterpoise (CP) procedure ${ }^{[40]}$ (see Section S1 in the Supporting Information for more details). All calculations (except the DLPNO-CCSD(T) calculations below) were done with Gaussian $09^{[41]}$ and used Gaussian's "ultrafine" integration grid and spherical harmonic basis functions.

We focused on the iodinated species for some extra investigations: (i) Trinitro- and tricyano-iodabenzene molecules complexed with $\mathrm{H}_{2} \mathrm{O}$ and $\mathrm{NH}_{3}$ were investigated; and (ii) the iodobenzene $\bullet \bullet \mathrm{H}_{2} \mathrm{O}$ complexes were studied at different levels of theory: mPW2-PLYP with the 6-31+G(d) and aug-cc-pVTZ basis sets, The M06-2X meta-hybrid functional ${ }^{[42]}$ with the $6-31+G(d)$ and aug-cc-pVTZ basis sets, and DLPNO-CCSD(T) (domain-based local pair natural orbital coupled cluster with single, double and perturbative triple excitations ${ }^{[43-45]}$ employing the minimally-augmented ma-def2-QZVP basis set, ${ }^{[46,47]}$ which uses the def2ECP pseudopotential for iodine. The def2-QZVPP/C fitting basis was used for the RI (Resolution of the 
Identity) part of the method. DLPNO-CCSD(T) is a linear-scaling method that typically recovers $99.9 \%$ of the full $\operatorname{CCSD}(T)$ correlation energy. ${ }^{[45]}$ The DLPNO-CCSD(T) calculations were done with ORCA ${ }^{[48,49]}$ and used tight SCF convergence and tight PNO thresholds.

Molecular electrostatic potential (MEP) surfaces were created for the optimised halogenabenzene, halobenzene and halocyclopentadiene $(\mathrm{X}=\mathrm{F}, \mathrm{Cl}, \mathrm{Br}, \mathrm{I}$ or $\mathrm{At})$ and trinitro- and tricyano-iodabenzene structures using GaussView. ${ }^{[50]}$ The electrostatic potentials were mapped on the 0.0005 electrons/Bohr ${ }^{3}$ electron density surfaces.

For selected structures harmonic vibrational frequencies were computed at the same level of theory, to verify the nature of the stationary point (minimum or transition state). The Cartesian coordinates of the optimised structures are included in the Supporting Information (Section S3).

\section{Results}

\subsection{X-bird $\bullet \bullet \mathrm{H}_{2} \mathrm{O}$ and X-bird $\bullet \bullet \mathrm{NH}_{3}$}

Figure 2 shows the MEP maps for the X-bird structures, in two different orientations. For the second orientation, the MEPs are also shown with a solid surface, which shows more clearly the location of the positive regions of electrostatic potential. The $\mathrm{Cl}$-bird structure does not show an obvious $\sigma$-hole. Instead, there are two clear positive regions around the "wing" hydrogens. From Br-bird onwards, electrondeficient blue regions start to appear at both sides of the halogen, roughly at the extension of the C-X bonds, which become more pronounced for the heavier halogens. At the same time the electron-deficient regions around the wing hydrogens become weaker. This is in agreement with a paper on ionic compounds involving bromomium and iodonium cations, where the halogen is also bonded to two carbon atoms. The halogens in these compounds are found to have $\sigma$-holes at the extensions of the $\mathrm{C}$-X bonds. ${ }^{[1]}$

$$
\mathrm{X}=\mathrm{Cl}
$$
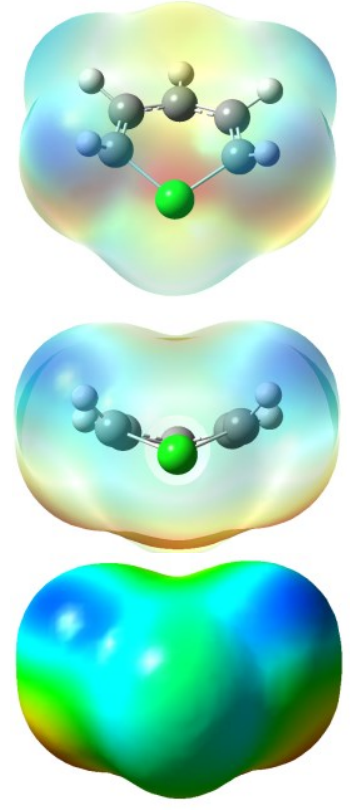

$\mathrm{X}=\mathrm{Br}$
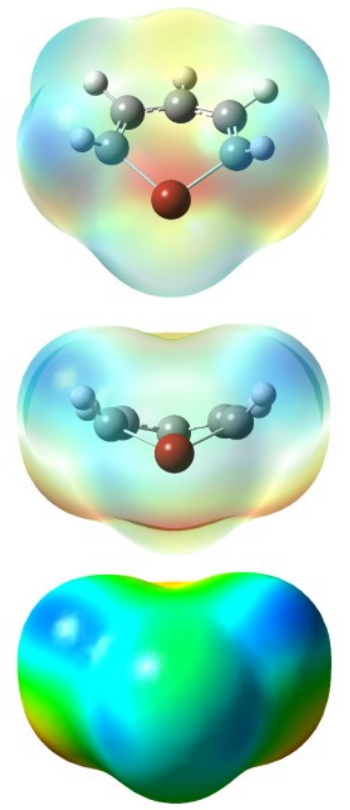

$X=1$
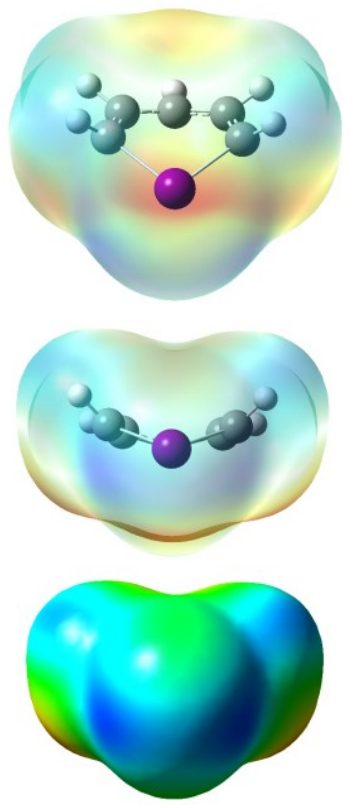

$X=A t$
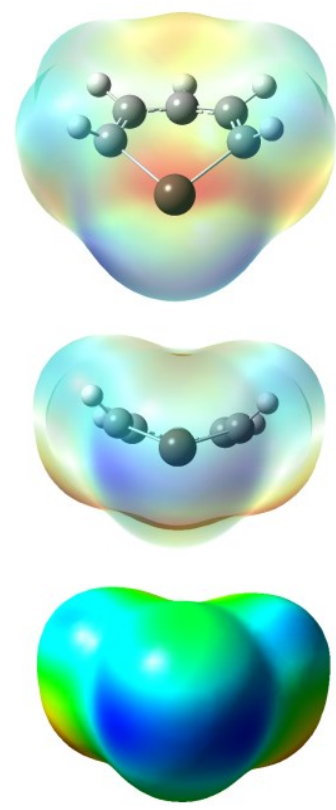
Figure 2. MEP maps for the bird halogenabenzene structures, mapped at the 0.0005 electrons/Bohr ${ }^{3}$ isodensity surface. Blue and red represent positive and negative regions of electrostatic potential, respectively.

Figure 3 shows the optimised structures of the X-bird $\bullet \bullet \mathrm{H}_{2} \mathrm{O}$ and $\mathrm{X}$-bird $\bullet \bullet \bullet \mathrm{NH}_{3}$ structures. The water or ammonia molecule is located between the halogen and an adjacent $\mathrm{C}-\mathrm{H}$ group. The oxygen is facing the halogen, whereas one of the water hydrogens points to the adjacent carbon atom. The oxygen is located roughly at the extension of the $\mathrm{C}-\mathrm{X}$ bond (with $\mathrm{CX} \bullet \bullet \mathrm{O}_{\mathrm{w}}$ angles of about $150^{\circ}$, see below), as predicted by the MEP maps. An equivalent symmetry-related minimum exists with the nucleophile between the halogen and the other neighbouring $\mathrm{C}-\mathrm{H}$ group. For At-bird $\bullet \bullet \mathrm{H}_{2} \mathrm{O}$, we found an additional minimum with a different water orientation and slightly smaller interaction energy (see Figure 3 ). This minimum was not found for the lighter halogens. Table 1 lists the interaction energies and geometrical parameters. X-bonds are expected to have vdW ratios below $1 .{ }^{[25]}$ The vdW ratios of $\mathrm{Cl}$-bird $\bullet \bullet \bullet \mathrm{H}_{2} \mathrm{O}, \mathrm{Br}$-bird $\bullet \bullet \mathrm{H}_{2} \mathrm{O}$ and $\mathrm{Cl}$ bird $\bullet \bullet \mathrm{NH}_{3}$ are at or just above 1.0. However, the interaction energies systematically increase (become more negative) and the vdW ratios decrease going down the halogen group, as would be expected for $\mathrm{X}$ bonds.

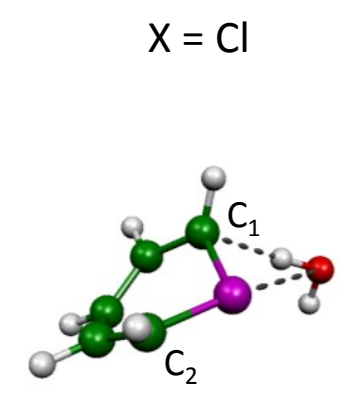

$-17.0$

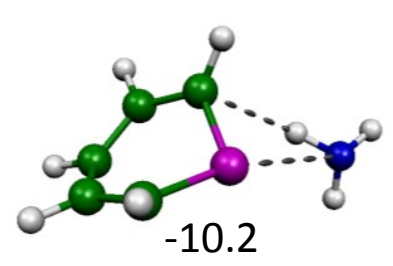

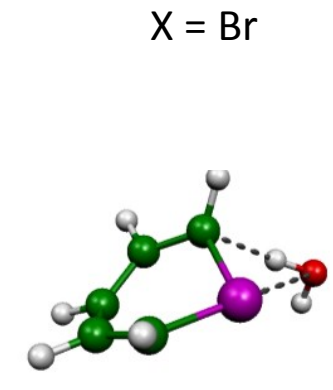

$-18.0$

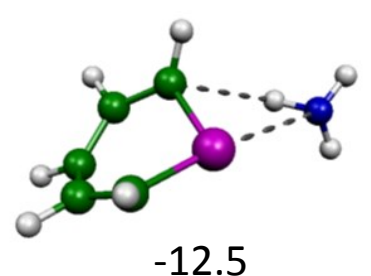

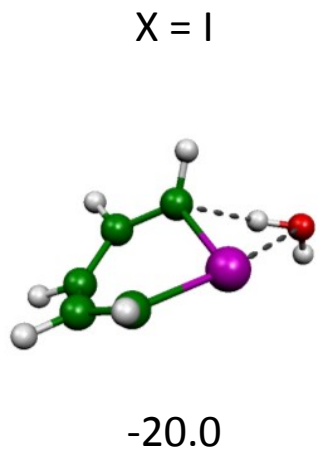
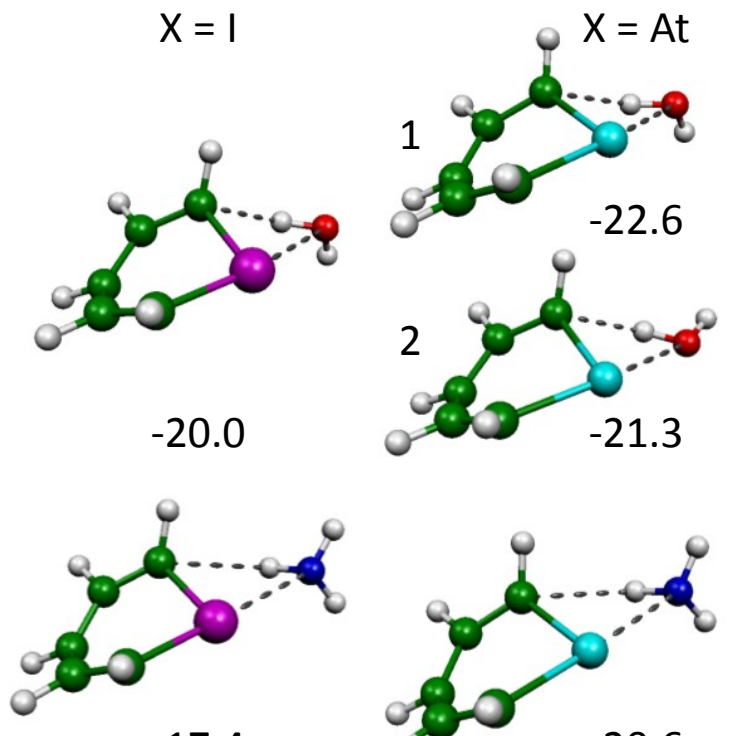

$-17.4$

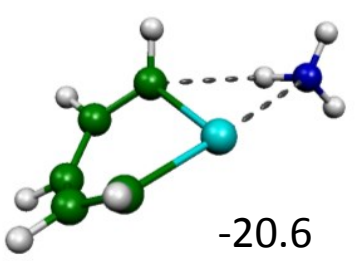

Figure 3. Optimised structures of the bird $\bullet \bullet \mathrm{H}_{2} \mathrm{O}$ and bird $\bullet \bullet \mathrm{NH}_{3}$ structures. Interaction energies (in $\mathrm{kJ} / \mathrm{mol}$ ) are given as well. The dotted lines highlight potential intermolecular interactions.

Table 1. CP-Corrected Interaction Energies $\Delta \mathrm{E}^{\mathrm{CP}}$ (in kJ/mol) and Geometrical Parameters (Distances in $\AA$; Angles in Degrees) of the Optimised X-Bird $\bullet \bullet \mathrm{H}_{2} \mathrm{O}$ and $\mathrm{X}$-Bird $\bullet \bullet \bullet \mathrm{NH}_{3}$ Structures ${ }^{\mathrm{a}}$

\begin{tabular}{lcccccc}
\hline X-bird $\bullet \bullet \mathrm{H}_{2} \mathrm{O}$ & $\Delta \mathrm{E}^{\mathrm{CP}}$ & $\mathrm{R}\left(\mathrm{C}_{1} \bullet \bullet \cdot \mathrm{H}_{\mathrm{w}}\right)$ & $\mathrm{R}\left(\mathrm{X} \bullet \bullet \bullet \mathrm{O}_{\mathrm{w}}\right)$ & $\angle \mathrm{O}_{\mathrm{w}} \mathrm{H}_{\mathrm{w}} \bullet \bullet \bullet \mathrm{C}_{1}$ & $\angle \mathrm{C}_{2} \mathrm{X} \bullet \bullet \bullet \mathrm{O}_{\mathrm{w}}$ & vdW ratio \\
\hline Cl-bird & -17.0 & 2.18 & 3.57 & 165 & 149 & 1.09 \\
Br-bird & -18.0 & 2.17 & 3.51 & 160 & 147 & 1.04 \\
I-bird & -20.0 & 2.19 & 3.32 & 146 & 152 & 0.95 \\
At-bird 1 & -22.6 & 2.18 & 3.22 & 143 & 153 & 0.91
\end{tabular}




\begin{tabular}{lcccccc} 
At-bird 2 & -21.3 & 2.20 & 3.19 & 143 & 151 & 0.90 \\
trinitro-I-bird & -27.9 & & 3.01 & & 158 & 0.86 \\
tricyano-I-bird & -42.2 & & 2.88 & & 173 & 0.82 \\
\hline $\mathrm{X}$-bird $\bullet \bullet \mathrm{NH}_{3}$ & $\Delta \mathrm{E}^{\mathrm{CP}}$ & $\mathrm{R}\left(\mathrm{C}_{1} \bullet \bullet \bullet \mathrm{H}_{\mathrm{n}}\right)$ & $\mathrm{R}\left(\mathrm{X} \bullet \bullet \mathrm{N}_{\mathrm{n}}\right)$ & $\angle \mathrm{N}_{\mathrm{n}} \mathrm{H}_{\mathrm{n}} \bullet \bullet \bullet \mathrm{C}_{1}$ & $\angle \mathrm{C}_{2} \mathrm{X} \bullet \bullet \mathrm{N}_{\mathrm{n}}$ & $\mathrm{vdW}$ ratio \\
\hline $\mathrm{Cl}-$ bird & -10.2 & 2.57 & 3.29 & 136 & 157 & 1.00 \\
$\mathrm{Br}-$ bird & -12.5 & 2.64 & 3.22 & 127 & 164 & 0.95 \\
I-bird & -17.4 & 2.74 & 3.16 & 117 & 167 & 0.89 \\
At-bird & -20.6 & 2.70 & 3.13 & 120 & 165 & 0.88 \\
trinitro-I-bird & -31.9 & & 3.06 & & 154 & 0.87 \\
tricyano-I-bird & -51.5 & & 2.84 & & 173 & 0.81 \\
\hline
\end{tabular}

${ }^{a} \mathrm{O}_{w}, \mathrm{H}_{w}$ are the water oxygen and hydrogen involved in the $\mathrm{H}$-bond/X-bond; $\mathrm{N}_{n}, \mathrm{H}_{n}$ are the ammonia oxygen and hydrogen involved in the $\mathrm{H}$-bond/X-bond, respectively. See Figure 3 for the definition of $\mathrm{C}_{1}$ and $C_{2}$. vdW ratio: the ratio of the sum of the van der Waals radii ${ }^{[52,53]}$ of $X$ and $\mathrm{O}_{w}$ (for $X$-bird $\bullet \bullet \mathrm{H}_{2} \mathrm{O}$ ) or $\mathrm{X}$ and $\mathrm{N}_{\mathrm{n}}$ (for $\mathrm{X}$-bird $\bullet \bullet \mathrm{NH}_{3}$ ) and the distance between the $\mathrm{X}$ and $\mathrm{O}_{\mathrm{w}}$ or $\mathrm{X}$ and $\mathrm{N}_{\mathrm{n}}$ atoms.

Aiming to stabilise the halogenabenzene bird structure, Rawashdeh et al. suggested putting nitro or cyano substituents in the para and ortho positions. ${ }^{[12]}$ The trinitro-iodabenzene and trinitro-bromabenzene structures were calculated to be planar, whereas the trinitro-chlorabenzene, trinitro-fluorabenzene and all tricyano-halogenabenzene structures retained the bird structure.

The MEP maps of trinitro-iodabenzene and tricyano-iodabenzene are shown in Figure 4 and are compared to the MEP map of iodabenzene. The maps for trinitro- and tricyano-iodabenzene show a much clearer $\sigma$ hole compared to non-substituted iodabenzene. As also found by Rawashdeh et al., ${ }^{[12]}$ the trinitroiodabenzene structure is planar, whereas the tricyano-iodabenzene structure keeps the bird form.
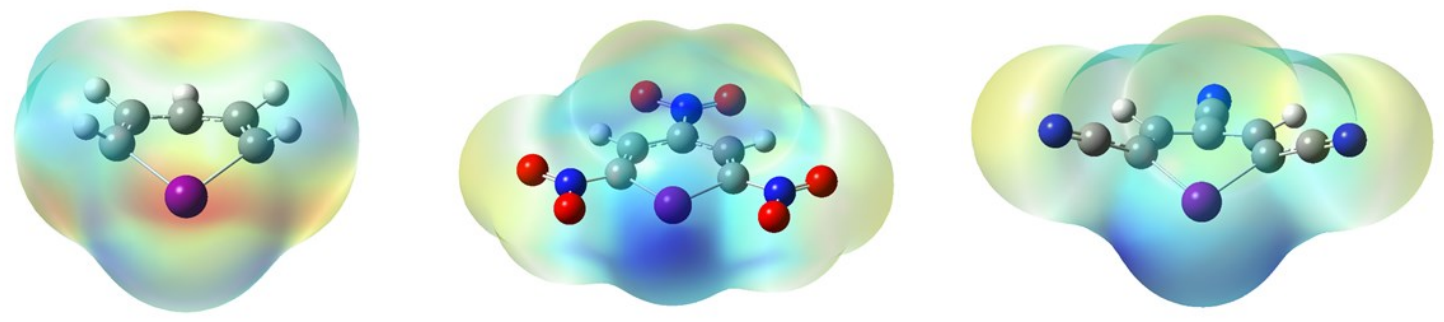

Figure 4. MEP maps for the iodabenzene, trinitro-iodabenzene and tricyano-iodabenzene structures, mapped at the 0.0005 electrons $/$ Bohr $^{3}$ isodensity surface. Blue and red represent positive and negative regions of electrostatic potential, respectively.

We optimised trinitro- and tricyano-iodabenzene structures interacting with $\mathrm{H}_{2} \mathrm{O}$ and $\mathrm{NH}_{3}$. The optimised complex structures are shown in Figure 5. Interaction energies and selected geometrical parameters are included in Table 1. 


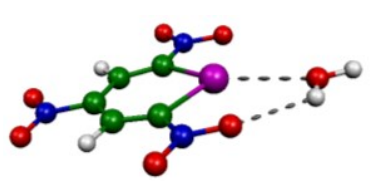

$-27.9$

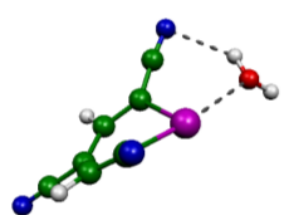

$-42.4$

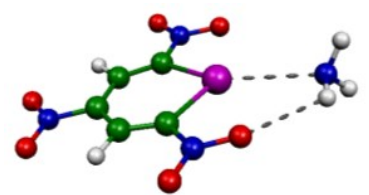

$-31.9$

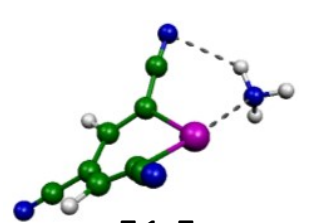

$-51.5$

Figure 5. Optimised structures of the tricyano-iodabenzene- and tricyano-iodabenzene structures interacting with $\mathrm{H}_{2} \mathrm{O}$ and $\mathrm{NH}_{3}$, with corresponding Interaction energies (in $\mathrm{kJ} / \mathrm{mol}$ ).

In all four trinitro/tricyano-iodabenzene $\bullet \bullet \mathrm{H}_{2} \mathrm{O} / \mathrm{NH}_{3}$ complexes secondary interactions are present: the trinitro complexes exhibit $\mathrm{NO}$ (nitro) $\bullet \bullet \mathrm{H}_{\mathrm{w} / \mathrm{n}}$ hydrogen bonds (H-bonds), whereas the tricyano complexes have $\mathrm{O}_{\mathrm{w}} \mathrm{H}_{\mathrm{w}} / \mathrm{N}_{\mathrm{n}} \mathrm{H}_{\mathrm{n}} \bullet \bullet \mathrm{N}$ (cyano) $\mathrm{H}$-bonds. The interaction energies are much larger, particularly for the cyano complexes, compared to unsubstituted iodabenzene, with shorter $X \bullet \bullet O_{w}$ and $X \bullet \bullet N_{n}$ distances and smaller vdW ratios (Table 1). Thus, the nitro and cyano substitutions clearly increase the halogen-bond strength.

We found another type of complex for the X-bird $\bullet \bullet \mathrm{H}_{2} \mathrm{O}$ structures, where the water is located "below" the bird, see Figure 6.

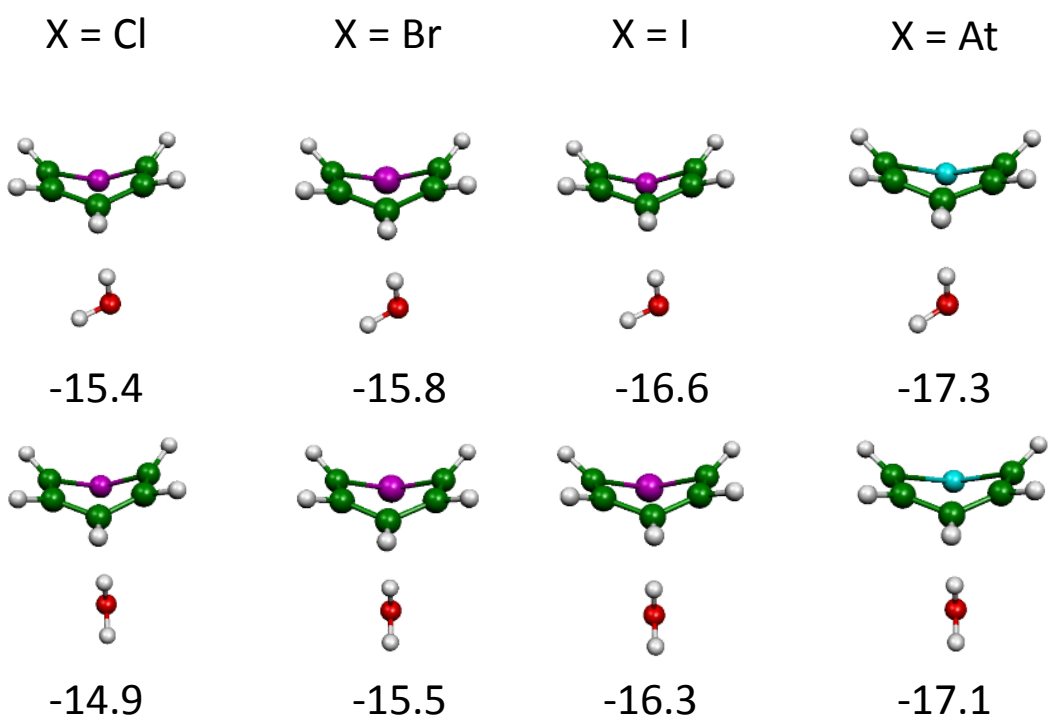

Figure 6. Optimised structures of the bird structures interacting with a $\mathrm{H}_{2} \mathrm{O}$ below the molecule. Interaction energies (in $\mathrm{kJ} / \mathrm{mol}$ ) are given as well. First row: $\mathrm{C}_{1}$-symmetric structures; Second row: $\mathrm{C}_{\mathrm{s}^{-}}$ 
symmetric structures. The $\mathrm{C}_{\mathrm{s}}$-symmetric structures are transition states for all halogens except At, for which this structure is a minimum.

In these, one of the water hydrogens is pointing towards the carbon atom opposite the halogen, which has a negative potential around it (see Figure 2; the red belt seen in these maps is located below the carbon atoms). The water oxygen is facing the halogen, but the small $\mathrm{O}_{\mathrm{w}} \bullet \bullet \bullet-\mathrm{X}$ angles (below $90^{\circ}$ ) prevent the oxygen from feeling the $\sigma$-hole; in addition, the $\mathrm{O}_{\mathrm{w}} \bullet \bullet \times \mathrm{X}$ distance (ranging from 3.73 for $\mathrm{Cl}$ to 3.89 for At) is too large for $X$-bonds. The $C_{1}$-symmetric structures in the first row of Figure 6 are minima, as evidenced by their all-positive vibrational frequencies. There exists a symmetry-equivalent minimum with the non-bonded water hydrogens pointing towards the other side of the central carbon atom. The $\mathrm{C}_{\mathrm{s}^{-}}$ symmetric structures in the lower row are transition states for $\mathrm{X}=\mathrm{Cl}, \mathrm{Br}$ and $\mathrm{I}$, as demonstrated by the presence of one imaginary frequency, but, interestingly, it is a minimum for $X=A t$. The imaginary value of the frequency in the $\mathrm{C}_{\mathrm{s}}$-symmetric structures systematically decreases with increasing size of the halogen and is positive for At $\left(\mathrm{Cl}:-51 \mathrm{~cm}^{-1}\right.$; $\mathrm{Br}:-34 \mathrm{~cm}^{-1}$; I: $-7 \mathrm{~cm}^{-1}$; At: $33 \mathrm{~cm}^{-1}$; see also Figure S2.1; Supporting Information). The $\mathrm{C}_{\mathrm{s}}$-symmetric structures are energetically very close to the $\mathrm{C}_{1}$-symmetric structures for all halogens $(\Delta \mathrm{E} \leq 0.5 \mathrm{~kJ} / \mathrm{mol})$. Thus, for $\mathrm{X}=\mathrm{Cl}, \mathrm{Br}$ and I the barrier between the two symmetry-equivalent $C_{1}$ minima is practically non-existent. For $X=A t$, there is an extremely low transition state between the $\mathrm{C}_{1}$ - and $\mathrm{C}_{\mathrm{s}}$-symmetric minima (Figure S2.2; Supporting Information). The harmonic frequency value of the vibrational mode corresponding to the transition from the X-bird $\bullet \bullet \mathrm{H}_{2} \mathrm{O}$ minimum to transition state lies between $81(\mathrm{X}=\mathrm{Cl})$ and $71 / 72(\mathrm{X}=\mathrm{l} / \mathrm{At}) \mathrm{cm}^{-1}$, corresponding to a zero-point energy contribution of $0.4-0.5 \mathrm{~kJ} / \mathrm{mol}$. This is of similar magnitude as the calculated barriers and there should therefore be nearly uninterrupted rotation of the water molecule in these structures, even at very low temperatures.

\subsection{X-cyclopentadiene $\bullet \bullet \bullet \mathrm{H}_{2} \mathrm{O}$ and $\mathrm{X}$-cyclopentadiene $\bullet \bullet \bullet \mathrm{NH}_{3}$}

Figure 7 shows the optimised X-cyclopentadiene $\bullet \bullet \mathrm{H}_{2} \mathrm{O}$ and X-cyclopentadiene $\bullet \bullet \mathrm{NH}_{3}$ structures. Selected geometrical parameters are collected in Table 2. For the complexes with $\mathrm{H}_{2} \mathrm{O}$, the $\mathrm{Cl}$ - and $\mathrm{Br}$ substituted cyclopentadienes do not form an X-bond. The water molecule is located above the cyclopentadiene ring, with one hydrogen pointing towards the $\pi$-electron cloud of the aromatic ring, whereas the other one points towards the negative belt of the halogen. The iodinated and astatinated cyclopentadienes do form X-bonds with a water molecule, as also evidenced by their vdW ratios, which are below 1, and nearly linear halogen-bond angles (see Table 2). For the structures with $\mathrm{NH}_{3}$, only the chlorinated cyclopentadiene does not form an X-bond. In Cl-cyclopentadiene $\bullet \bullet \mathrm{NH}_{3}$, the $\mathrm{NH}_{3}$ molecule binds to cyclopentadiene via two unconventional $\mathrm{H}$-bonds: A C-H $\bullet \bullet \mathrm{N}_{n}$ bond and an $\mathrm{N}_{n}-\mathrm{H}_{n} \bullet \bullet C l$ bond. The interaction energies of the halogen-bonded $\mathrm{Br}-$, I- and At-cyclopentadiene $\bullet \bullet \mathrm{NH}_{3}$ structures increase approximately linearly with increasing row number of the halogen. Their vdW ratios are below 1 (and decreasing going down the halogen group) and halogen-bond angles near linearity. In general, the $\mathrm{X}$ bonds with $\mathrm{NH}_{3}$ are slightly stronger than those with $\mathrm{H}_{2} \mathrm{O}$. 


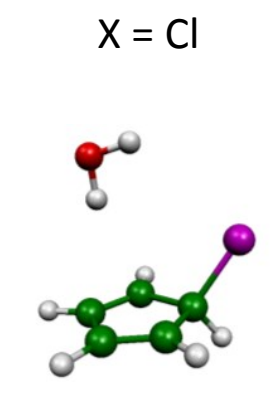

$-11.9$

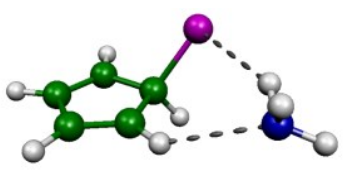

$-11.7$

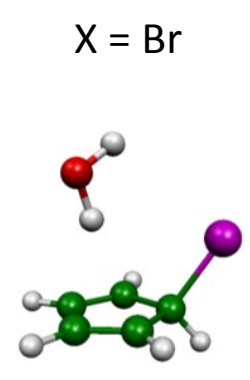

$-11.8$

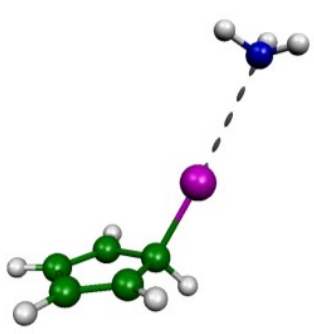

$-5.1$

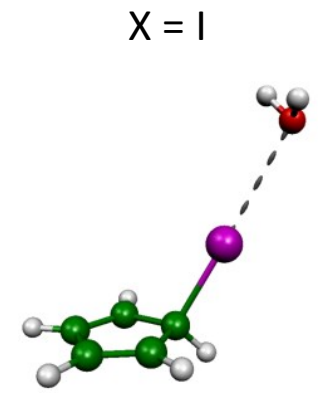

$-7.8$

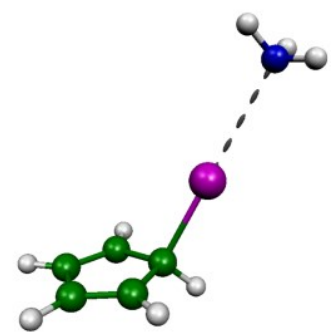

$-12.3$

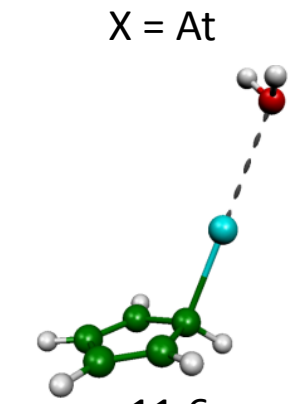

$-11.6$

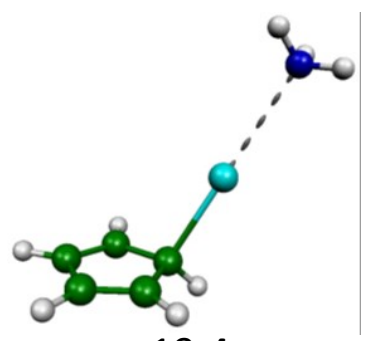

$-19.4$

Figure 7. Optimised structures of the X-cyclopentadiene- $\mathrm{H}_{2} \mathrm{O}$ and X-cyclopentadiene- $\mathrm{NH}_{3}$ structures. Interaction energies (in $\mathrm{kJ} / \mathrm{mol}$ ) are given as well.

Table 2. CP-Corrected Interaction Energies $\Delta \mathrm{E}^{\mathrm{CP}}$ (in kJ/mol) and Geometrical Parameters (Distances in $\AA$; Angles in Degrees) of the Optimised X-Cyclopentadiene $\bullet \bullet \mathrm{H}_{2} \mathrm{O}$ and X-Cyclopentadiene $\bullet \bullet \mathrm{NH}_{3}$ Structures

\begin{tabular}{lcccc}
\hline X-penta $\bullet \bullet \mathrm{H}_{2} \mathrm{O}^{a}$ & $\Delta \mathrm{E}^{\mathrm{CP}}$ & $\mathrm{R}\left(\mathrm{X} \bullet \bullet \bullet \mathrm{O}_{w}\right)$ & $\angle \mathrm{CX} \bullet \bullet \mathrm{O}_{\mathrm{w}}$ & vdW ratio \\
\hline Cl-penta & -11.9 & 3.70 & 86 & 1.13 \\
Br-penta & -11.8 & 3.89 & 82 & 1.15 \\
I-penta & -7.8 & 3.27 & 178 & 0.93 \\
At-penta & -11.6 & 3.09 & 179 & 0.87 \\
\hline X-penta $\bullet \bullet \mathrm{NH}_{3}$ & $\Delta \mathrm{E}^{\mathrm{CP}}$ & $\mathrm{R}\left(\mathrm{X} \bullet \bullet \bullet \mathrm{N}_{\mathrm{n}}\right)$ & $\angle \mathrm{CX} \bullet \bullet \mathrm{N}_{\mathrm{n}}$ & vdW ratio \\
\hline Cl-penta & -11.7 & 3.68 & 86 & 1.11 \\
Br-penta & -5.1 & 3.19 & 176 & 0.94 \\
I-penta & -12.3 & 3.09 & 180 & 0.88 \\
At-penta & -19.4 & 3.00 & 180 & 0.84 \\
\hline
\end{tabular}

${ }^{\mathrm{a}}$ penta $=$ cyclopentadiene

\subsection{Halobenzene $\bullet \bullet \bullet \mathrm{H}_{2} \mathrm{O}$ and halobenzene $\bullet \bullet \mathrm{NH}_{3}$}

Figure 8 shows the structures and interaction energies of the halobenzene $\bullet \bullet \mathrm{H}_{2} \mathrm{O}$ and halobenzene $\bullet \bullet \mathrm{NH}_{3}$ structures, whereas selected geometrical parameters are included in Table 3 . 


$$
\mathrm{X}=\mathrm{Cl}
$$

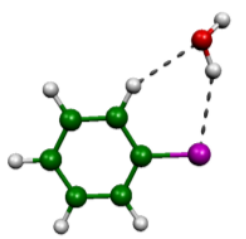

$-12.5$

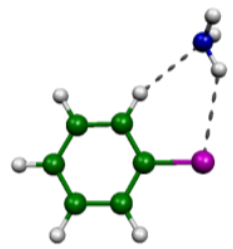

$-10.9$
$\mathrm{X}=\mathrm{Br}$

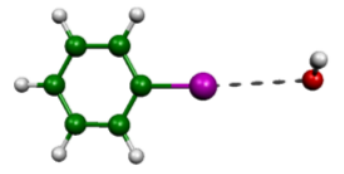

$-4.6$

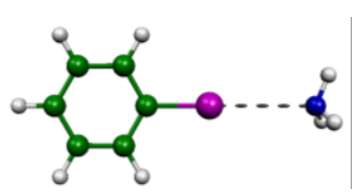

$-6.1$
$X=1$

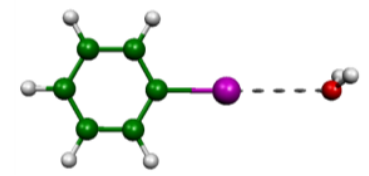

$-8.1$

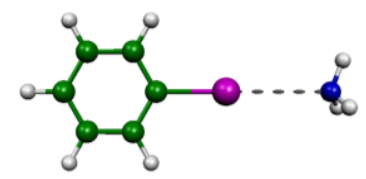

$-12.1$
$X=A t$

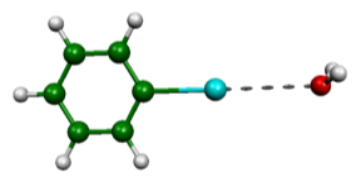

$-11.6$

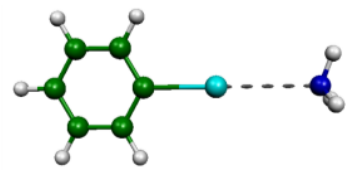

$-17.9$

Figure 8. Optimised structures of the halobenzene $\bullet \bullet \mathrm{H}_{2} \mathrm{O}$ and halobenzene $\bullet \bullet \mathrm{NH}_{3}$ structures. Interaction energies (in $\mathrm{kJ} / \mathrm{mol}$ ) are given as well.

Chlorobenzene clearly does not form an X-bond with either $\mathrm{H}_{2} \mathrm{O}$ or $\mathrm{NH}_{3}$. This is in agreement with previous work on halobenzene $\bullet \bullet \mathrm{H}_{2} \mathrm{O}$, conducted at the M06-2X/6-31+G(d) level of theory, where also only the complexes with halogens heavier than $\mathrm{Cl}$ were found to form X-bonds. ${ }^{[10]}$ In the complexes with chlorobenzene, one of the hydrogens of $\mathrm{H}_{2} \mathrm{O}$ or $\mathrm{NH}_{3}$ forms a $\mathrm{H}$-bond with $\mathrm{Cl}$ at a (near-)perpendicular angle; the hydrogen obviously points to the negative belt around the halogen. A second $\mathrm{H}$-bond is formed between a $\mathrm{C}-\mathrm{H}$ bond of chlorobenzene and the $\mathrm{O}$ or $\mathrm{N}$ atom of $\mathrm{H}_{2} \mathrm{O}$ or $\mathrm{NH}_{3}$. The heavier halogens do form $\mathrm{X}$-bonds. This is also evidenced from the structural parameters included in Table 3, which show near-linear halogen-bond angles and vdW ratios that are clearly below 1 for these complexes. The complexes with $\mathrm{NH}_{3}$ are more stable than those with $\mathrm{H}_{2} \mathrm{O}$.

Table 3. CP-Corrected Interaction Energies $\Delta \mathrm{E}^{\mathrm{CP}}$ (in $\mathrm{kJ} / \mathrm{mol}$ ) and Geometrical Parameters (Distances in $\AA$; Angles in Degrees) of the Optimised Halobenzene $\bullet \bullet \mathrm{H}_{2} \mathrm{O}$ and Halobenzene $\bullet \bullet \mathrm{NH}_{3}$ Structures

\begin{tabular}{lrccc}
\hline X-benzene- $\mathrm{H}_{2} \mathrm{O}$ & $\Delta \mathrm{E}^{\mathrm{CP}}$ & $\mathrm{R}\left(\mathrm{X} \bullet \bullet \mathrm{O}_{\mathrm{w}}\right)$ & $\angle \mathrm{CX} \bullet \bullet \mathrm{O}_{\mathrm{w}}$ & vdW ratio \\
\hline Cl-benzene & -12.5 & 3.41 & 92 & 1.04 \\
Br-benzene & -4.6 & 3.19 & 176 & 0.95 \\
I-benzene & -8.1 & 3.17 & 179 & 0.90 \\
At-benzene & -11.6 & 3.11 & 179 & 0.88 \\
\hline X-benzene- $\mathrm{NH}_{3}$ & $\Delta \mathrm{E}^{\mathrm{CP}}$ & $\mathrm{R}\left(\mathrm{X} \bullet \bullet \bullet \mathrm{N}_{\mathrm{n}}\right)$ & $\angle \mathrm{CX} \bullet \bullet \mathrm{N}_{\mathrm{n}}$ & vdW ratio \\
\hline Cl-benzene & -10.9 & 3.71 & 90 & 1.12 \\
Br-benzene & -6.1 & 3.20 & 180 & 0.94 \\
I-benzene & -12.1 & 3.15 & 180 & 0.89 \\
At-benzene & -17.9 & 3.08 & 180 & 0.86 \\
\hline
\end{tabular}


The halogen-bond energies displayed in Table 3 are smaller than those computed with M06-2X/6-31+G(d) in our previous work $\left(-7.3,-13.3\right.$ and $-18.6 \mathrm{~kJ} / \mathrm{mol}$ for $\mathrm{X}=\mathrm{Br}$, I and At, respectively). ${ }^{[10]}$ To assess the accuracy of the level of theory used in the current work, we calculated the iodobenzene $\bullet \bullet \mathrm{H}_{2} \mathrm{O}$ interaction energy with different method/basis set combinations (Table 4). The geometries of all complexes were optimised at the same level of theory as used for the energy calculation, except the DLPNO-CCSD(T) calculations, which were single-point calculations at the mPW2-PLYP/aug-cc-pVTZ geometry. To assess the effect of halogen-bond distance optimisation, two further DLPNO-CCSD(T) calculations were performed at the mPW2-PLYP/aug-cc-pVTZ geometry with the $\mathrm{X} \bullet \bullet O$ distance elongated by 0.05 and $0.10 \AA$. For the single-point calculations only the "vertical" CP-corrected interaction energy $\Delta \mathrm{E}^{\mathrm{CP}}$ (vert) (i.e. excluding deformation energies) was calculated (see Section $\mathrm{S} 1$ in the Supporting Information for more details). Comparison of the $\Delta \mathrm{E}^{\mathrm{CP}}$ (vert) and $\triangle \mathrm{E}^{\mathrm{CP}}$ values for the $\mathrm{mPW}$ 2-PLYP and M06$2 X$ calculations indicates that the deformation energies are generally small. The M06-2X/6-31+G(d) interaction energy in Table 4 differs slightly from that in Ref. ${ }^{[10]}$, because in Ref. ${ }^{[10]}$ the geometries were optimised on the CP-corrected potential energy surface.

Table 4. $\mathrm{CP}$-Corrected Interaction Energies $\Delta \mathrm{E}^{\mathrm{CP}}$ and $\Delta \mathrm{E}^{\mathrm{CP}}$ (Vert) and $\mathrm{BSSE}$ Values (All in $\mathrm{kJ} / \mathrm{mol}$ ) of lodobenzene $\bullet \bullet \mathrm{H}_{2} \mathrm{O}$ at Different Levels of Theory

\begin{tabular}{lcccc}
\hline Level of theory & Geometry & $\Delta \mathrm{E}^{\mathrm{CP}}(\text { vert })^{\mathrm{a}}$ & $\Delta \mathrm{E}^{\mathrm{CP}}$ & \multicolumn{1}{c}{$\mathrm{BSSE}$} \\
\hline mPW2-PLYP/aug-cc-pVTZ & Optimised & -8.18 & -8.12 & -1.15 \\
mPW2-PLYP/6-31+G(d) & Optimised & -9.50 & -9.41 & -4.92 \\
M06-2X/aug-cc-pVTZ & Optimised & -9.67 & -9.60 & -0.32 \\
M06-2X/6-31+G(d) & Optimised & -13.95 & -12.98 & -3.63 \\
DLPNO-CCSD(T)/ma-def2-QZVP & Single-point & -8.00 & & -1.19 \\
DLPNO-CCSD(T)/ma-def2-QZVP & $+0.05 \AA^{\mathrm{c}}$ & -8.09 & & -1.09 \\
DLPNO-CCSD(T)/ma-def2-QZVP & $+0.10 \AA^{\mathrm{c}}$ & -8.05 & & -1.01 \\
\hline
\end{tabular}

a "Vertical" CP-corrected interaction energy (excluding deformation energies)

${ }^{b}$ Single-point calculation at mPW2-PLYP/aug-cc-pVTZ geometry

${ }^{c}$ At mPW2-PLYP/sug-cc-pVTZ geometry, with the X-bond distance elongated by 0.05 or $0.10 \AA$

The values in Table 4 show that switching to the larger basis set in the M06-2X calculations reduces $\Delta \mathrm{E}^{\mathrm{CP}}$. Going from M06-2X to mPW2-PLYP (at the same basis set level) sees a further reduction in the interaction energy. The reference DLPNO-CCSD(T)/ma-def2-QZVP results are nearly identical to the $\mathrm{mPW} 2-\mathrm{PLYP} /$ augcc-pVTZ values. We therefore believe this level of theory is accurate for calculating $X$-bond energies. A recent review of methods for studying $X$-bonds also identified double hybrids are the best class of density functionals for these interactions. ${ }^{[19]}$ Another study concluded that M06-2X performs better than B3LYP for halogen-bonding interactions, but did not consider double hybrids. ${ }^{[54]}$

Lin and MacKerell ${ }^{[5]}$ studied complexes of halobenzenes and halogenated ethane molecules (with halogens ranging from fluorine to bromine) with model compounds serving as $\mathrm{H}$-bond donors and $\mathrm{H}$-bond acceptors in both perpendicular $\left(\mathrm{C}-\mathrm{X} \bullet \bullet \mathrm{Y}=90^{\circ}\right)$ and linear $\left(\mathrm{C}-\mathrm{X} \bullet \bullet \mathrm{Y}=180^{\circ}\right)$ orientations $(\mathrm{X}=$ halogen; $\mathrm{Y}$ $=\mathrm{O}$ or $\mathrm{N}$ in model compound). They concluded that halogens acting as $\mathrm{H}$-bond acceptors may make a more favorable contribution to ligand binding than X-bonds. Whereas in the current paper we focus on Xbonds, we did consider complexes with the water molecule located above the halobenzene, acting as $\mathrm{H}$ bond donor to the negative belt of the halogen. Lin and Mackerell contrasted such perpendicular 
structures with linear halogen-bonded complexes using rigid scans of the intermolecular distance at the RIMP2/aug-cc-pVQZ level with counterpoise correction, and found the perpendicular complexes more favored than the linear ones. In our work, however, full optimisation at the mPW2-PLYP/aug-cc-pVTZ level resulted in double-hydrogen-bonded structures with the water located between the $\mathrm{C}-\mathrm{X}$ and a neighbouring $\mathrm{C}-\mathrm{H}$ group; the chlorobenzene $\bullet \bullet \mathrm{H}_{2} \mathrm{O}$ structure is identical to that in in Figure 8 and the other halogens form similar structures (Figure S2.3, Supporting Information). This is despite a rigid scan with the intermolecular distance varied showing a clear minimum for Cl-benzene $\bullet \bullet \mathrm{H}_{2} \mathrm{O}$ (Figure S2.4, Supporting Information). Presumably this minimum disappears when allowing for geometry relaxation. The interaction energies of the double-hydrogen-bonded complexes are -12.5, -12.5, -12.1 and -11.6 $\mathrm{kJ} / \mathrm{mol}$ for $\mathrm{X}=\mathrm{Cl}, \mathrm{Br}$, I and At, respectively. Thus, whereas these are preferred over the halogen-bonded halobenzene $\bullet \bullet \mathrm{H}_{2} \mathrm{O}$ complexes, for the heavier halogens the interaction energies are similar. This was also observed for halogenated uracil $\bullet \bullet \mathrm{H}_{2} \mathrm{O} .{ }^{[22,23]}$ Thus, whereas halogen-hydrogen-bond donor interactions may be more favorable than halogen bonding interactions for the lighter halogens, as suggested by Lin and MacKerell, ${ }^{[55]}$ this may not necessarily be the case for the heavier halogens.

\section{Conclusions}

We investigated the ability of two $\mathrm{C}_{5} \mathrm{H}_{5} \mathrm{X}$ molecules (halogenabenzene and 5-halocyclopenta-1,3-diene) and halobenzene $\left(\mathrm{C}_{6} \mathrm{H}_{5} \mathrm{X}\right)$, with $\mathrm{X}=\mathrm{Cl}, \mathrm{Br}$, I and At, to form halogen bonds with $\mathrm{H}_{2} \mathrm{O}$ and $\mathrm{NH}_{3}$ using the mPW2PLYP double-hybrid density functional and the aug-cc-pVTZ basis set (aug-cc-pVTZ-PP for I and At). A method comparison focal study using iodobenzene $\bullet \bullet \mathrm{H}_{2} \mathrm{O}$ showed that this level of theory gives interaction energies and halogen-bond distances in excellent agreement with DLPNO-CCSD(T)/ma-def2QZVP results.

For the bird-like halogenabenzene molecules, complexes are formed with the $\mathrm{H}_{2} \mathrm{O}$ or $\mathrm{NH}_{3}$ molecules located between the halogen and a neighbouring $\mathrm{C}-\mathrm{H}$ bond, forming two interactions: a (water) $\mathrm{O}-\mathrm{H} \bullet \bullet \bullet \mathrm{C}$ or (ammonia) $\mathrm{N}-\mathrm{H} \bullet \bullet C$ interaction and a $\mathrm{C}-\mathrm{X} \bullet \bullet \bullet \mathrm{O}$ (water) or $\mathrm{C}-\mathrm{X} \bullet \bullet \mathrm{N}$ (ammonia) interaction. Molecular electrostatic potential maps show regions of depleted electron density ( $\sigma$-holes) roughly at the extension of the C-X bonds, approximately where the halogen-bond acceptor is located in the complexes. The C$X \bullet \bullet O$ (water) angles $\left(\sim 140-160^{\circ}\right)$ and $C-X \bullet \bullet N\left(\right.$ ammonia) angles $\left(120-140^{\circ}\right)$ deviate from linearity presumably because (i) the $\sigma$-hole is not exactly at the extension of the $\mathrm{C}-\mathrm{X}$ bond and (ii) of the presence of the secondary (water) $\mathrm{O}-\mathrm{H} \bullet \bullet \mathrm{C}$ or ammonia) $\mathrm{N}-\mathrm{H} \bullet \bullet \mathrm{C}$ interaction. Previous work showed that significantly non-linear halogen bonds are feasible (even when the $\sigma$-hole is exactly at the extension of the $\mathrm{C}-\mathrm{X}$ bond), due to the presence of secondary interactions. ${ }^{[22]}$ Whereas the $\mathrm{Cl}-\mathrm{bird} \bullet \bullet \bullet \mathrm{H}_{2} \mathrm{O}, \mathrm{Br}$ bird $\bullet \bullet \mathrm{H}_{2} \mathrm{O}$ and $\mathrm{Cl}$-bird $\bullet \bullet \mathrm{NH}_{3}$ structures have vdW ratios at or just above 1.0, the vdW ratios of the complexes with the heavier halogens are below 1.0 as expected for halogen bonds, and the trend in interaction energy (which decreases upon descending the halogen group in the periodic table) is consistent with the interaction constituting a halogen bond. We therefore believe the complexes of the bird halogenabenzene molecule with $\mathrm{H}_{2} \mathrm{O}$ and $\mathrm{NH}_{3}$ can be classified as being halogen-bonded. The halogen-bond interaction is strengthened upon substitution of hydrogens by nitro or cyano substituents in the para and ortho positions. Another $\mathrm{X}$-bird $\bullet \bullet \bullet \mathrm{H}_{2} \mathrm{O}$ structure was found, where the water is located "below" the bird with a water hydrogen pointing towards the carbon opposite of the halogen. These are not halogen-bonded structures.

An isomer of halogenabenzene, 5-halocyclopenta-1,3-diene, is found to form clear halogen bonds with $\mathrm{H}_{2} \mathrm{O}$ for halogens heavier than bromine and with $\mathrm{NH}_{3}$ for halogens heavier than chlorine. The vdW ratios are below 1.0 and the halogen-bond angles close to linear $\left(\mathrm{C}-\mathrm{X} \bullet \bullet \mathrm{O}\right.$ angles of $\left.176-180^{\circ}\right)$. The interaction 
energies are less negative than those of the complexes with the bird halogenabenzene molecules, presumably because the latter ones have secondary interactions.

We also considered halogen bonds with the more conventional halobenzene molecule. Chlorobenzene does not form halogen bonds with $\mathrm{H}_{2} \mathrm{O}$ or $\mathrm{NH}_{3}$, but the molecules containing the heavier halogens do. We also investigated hydrogen-bonded halobenzene $\bullet \bullet \mathrm{H}_{2} \mathrm{O}$ complexes with the water molecule located in a perpendicular arrangement above the halobenzene. These were found not to be stable, but converged towards complexes where the water is located between the $\mathrm{C}-\mathrm{X}$ and a neighbouring $\mathrm{C}-\mathrm{H}$ bond, forming two H-bonds.

The halogen-bonded complexes with the $\mathrm{X}$-bird molecule are more stable (interaction energies ranging from -17.0 to $-22.6 \mathrm{~kJ} / \mathrm{mol}$ for $\mathrm{Cl}$-bird $\bullet \bullet \mathrm{H}_{2} \mathrm{O}$ to At-bird $\bullet \bullet \mathrm{H}_{2} \mathrm{O}$ ) than the more conventional halogenbonded halocyclopentadiene complexes $\left(-7.8\right.$ and $-11.6 \mathrm{~kJ} / \mathrm{mol}$ for I-cyclopentadiene $\bullet \bullet \mathrm{H}_{2} \mathrm{O}$ and Atcyclopentadiene $\bullet \bullet \mathrm{H}_{2} \mathrm{O}$, respectively) and halogen-bonded halobenzene complexes (-4.6 to -11.6 for $\mathrm{Br}$ benzene $\bullet \bullet \mathrm{H}_{2} \mathrm{O}$ to At-benzene $\bullet \bullet \mathrm{H}_{2} \mathrm{O}$ ). Switching the nucleophile from $\mathrm{H}_{2} \mathrm{O}$ to $\mathrm{NH}_{3}$ leads to slightly smaller interaction energies for the $\mathrm{X}$-bird complexes and to slightly larger interaction energies for the halobenzene and $\mathrm{X}$-cyclopentadiene complexes. The halobenzene $\bullet \bullet \mathrm{H}_{2} \mathrm{O}$ complexes where the halogen acts as a $\mathrm{H}$-bond acceptor are more stable than the halogen-bonded halobenzene $\bullet \bullet \bullet \mathrm{H}_{2} \mathrm{O}$ structures for $\mathrm{X}$ $=\mathrm{Br}$ or I, but for At the halogen-bonded complex is of similar stability as the hydrogen-bonded structure. Thus halogen-bonded interactions can be of similar or larger magnitude than in complexes where the halogen acts as hydrogen-bond acceptor if additional stabilising interactions are present (as for the X-bird complexes) or for the heavier halogens.

\section{Acknowledgement}

We thank EastCHEM for support via the EaStCHEM Research Computing Facility. The research data supporting this publication cab be accessed at https://doi.org/10.17630/a3b1f172-dd54-4df1-a4989951cfce9cee

Keywords: halogen bond, halogenabenzene, halobenzene, halocyclopentadiene, double hybrid density functional theory

\section{Supplementary Material}

Calculation of counterpoise-corrected interaction energies. Supplementary figures. Cartesian coordinates of optimised structures.

\section{References}

[1] H. Yin; Y. Wada; T. Kitamura; S. Yanagida. Environ. Sci. Technol. 2001, 35, 227-231.

[2] H. Mohan; J. P. Mittal. Chem. Phys. Lett. 2002, 364, 599-607.

[3] W. Shi; Y. Wang; Z. Jiao; J. Wang; G. Ding; J. Fu. Environ. Technol. 2009, 30, 191-197.

[4] T. Mondal; S. R. Reddy; S. Mahapatra. J. Chem. Phys. 2012, 137, 054311.

[5] A. Siporska; J. Szydłowski. J. Chem. Thermodyn. 2015, 88, 22-29.

[6] A. A. Khachatrian; Z. I. Shamsutdinova; M. A. Varfolomeev. Thermochim. Acta 2016, 645, 1-6.

[7] M. J. S. Monte; A. R. R. P. Almeida. Chemosphere 2017, 189, 590-598.

[8] W. Qiao; F. Luo; L. Lomheim; E. E. Mack; S. Ye; J. Wu; E. A. Edwards. Environ. Sci. Technol. 2018, 52, 13391-13398. 
[9] M. P. Sulbaek Andersen; J. W. Lengkong; J. Wallberg; F. Hasager; K. Vo; S. T. Andersen; H. G. Kjaergaard; T. J. Wallington; O. J. Nielsen. Phys. Chem. Chem. Phys. 2018, 20, 28796-28809.

[10] S. W. L. Hogan; T. van Mourik. J. Comput. Chem. 2019, 40, 554-561.

[11] M. N. Glukhovtsev. Russ. J. Org. Chem. 1991, 108, 5299-5358.

[12] A. M. Rawashdeh; P. Chakkingal Parambil; T. Zeng; R. Hoffmann. J. Am. Chem. Soc. 2017, 139, 7124-7129.

[13] Y. Wang; Y. Liu; X. Zheng. Int. J. Quant. Chem. 2018, 118, e25704.

[14] Z. Xu; Z. Yang; Y. Liu; Y. Lu; K. Chen; W. Zhu. J. Chem. Inf. Model. 2014, 54, 69-78.

[15] P. Politzer; P. Lane; M. Concha; Y. Ma; J. Murray. J. Mol. Model. 2007, 13, 305-311.

[16] A. C. Legon. Phys. Chem. Chem. Phys. 2010, 12, 7736-7747.

[17] P. Politzer; J. S. Murray. ChemPhysChem 2013, 14, 278-294.

[18] R. Wilcken; M. O. Zimmermann; A. Lange; A. C. Joerger; F. M. Boeckler. J. Med. Chem. 2013, 56, 1363-1388.

[19] L. P. Wolters; P. Schyman; M. J. Pavan; W. L. Jorgensen; F. M. Bickelhaupt; S. Kozuch. Wiley Interdisciplinary Reviews: Computational Molecular Science 2014, 4, 523-540.

[20] G. Cavallo; P. Metrangolo; R. Milani; T. Pilati; A. Priimagi; G. Resnati; G. Terraneo. Chem. Rev. 2016, $116,2478-2601$.

[21] M. H. Kolář; P. Hobza. Chem. Rev. 2016, 116, 5155-5187.

[22] S. W. L. Hogan; T. van Mourik. J. Comput. Chem. 2016, 37, 763-770.

[23] S. W. L. Hogan; T. van Mourik. J. Comput. Chem. 2017, 38, 933-933.

[24] G. Huan; T. Xu; R. Momen; L. Wang; Y. Ping; S. R. Kirk; S. Jenkins; T. van Mourik. Chem. Phys. Lett. 2016, 662, 67-72.

[25] G. R. Desiraju; P. S. Ho; L. Kloo; A. C. Legon; R. Marquardt; P. Metrangolo; P. Politzer; G. Resnati; K. Rissanen. Pure Appl. Chem. 2013, 85, 1711-1713.

[26] Q.-Z. Li; B. Jing; R. Li; Z.-B. Liu; W.-Z. Li; F. Luan; J.-B. Cheng; B.-A. Gong; J.-Z. Sun. Phys. Chem. Chem. Phys. 2011, 13, 2266-2271.

[27] P. Auffinger; F. A. Hays; E. Westhof; P. S. Ho. Proc. Natl. Acad. Sci. USA 2004, 101, 16789-16794.

[28] T. Clark; M. Hennemann; J. Murray; P. Politzer. J. Mol. Model. 2007, 13, 291-296.

[29] Y. Geboes; N. Nagels; B. Pinter; F. De Proft; W. A. Herrebout. J. Phys. Chem. A 2015, 119, 25022516.

[30] W. Li; Y. Zeng; X. Li; Z. Sun; L. Meng. J. Comput. Chem. 2015, 36, 1349-1358.

[31] A. J. Parker; J. Stewart; K. J. Donald; C. A. Parish. J. Am. Chem. Soc. 2012, 134, 5165-5172.

[32] M. R. Scholfield; M. C. Ford; C. M. Vander Zanden; M. M. Billman; P. S. Ho; A. K. Rappé. J. Phys. Chem. B 2015, 119, 9140-9149.

[33] W. Tian; Q. Li. Int. J. Quant. Chem. 2015, 115, 99-105.

[34] H. Wang; H. K. Bisoyi; A. M. Urbas; T. J. Bunning; Q. Li. Chem. Eur. J. 2019, 25, 1369-1378.

[35] S. Grimme; T. Schwabe. Phys. Chem. Chem. Phys. 2006, 8, 4398-4401.

[36] T. H. Dunning Jr. J. Chem. Phys. 1989, 90, 1007.

[37] R. A. Kendall; T. H. Dunning Jr.; R. J. Harrison. J. Chem. Phys. 1992, 96, 6796.

[38] K. A. Peterson; D. Figgen; E. Goll; H. Stoll; M. Dolg. J. Chem. Phys. 2003, 119, 11113-11123.

[39] K. A. Peterson; B. C. Shepler; D. Figgen; H. Stoll. J. Phys. Chem. A. 2006, 110, 13877-13883.

[40] S. F. Boys; F. Bernardi. Mol. Phys. 1970, 19, 553-566.

[41] M. J. Frisch; G. W. Trucks; H. B. Schlegel; G. E. Scuseria; M. A. Robb; J. R. Cheeseman; G. Scalmani; V. Barone; B. Mennucci; G. A. Petersson; H. Nakatsuji; M. Caricato; X. Li; H. P. Hratchian; A. F. Izmaylov; J. Bloino; G. Zheng; J. L. Sonnenberg; M. Hada; M. Ehara; K. Toyota; R. Fukuda; J. Hasegawa; M. Ishida; T. Nakajima; Y. Honda; O. Kitao; H. Nakai; T. Vreven; J. Montgomery, J. A.; J. E. Peralta; F. Ogliaro; M. Bearpark; J. J. Heyd; E. Brothers; K. N. Kudin; V. N. Staroverov; R. Kobayashi; J. Normand; K. Raghavachari; A. Rendell; J. C. Burant; S. S. Iyengar; J. Tomasi; M. Cossi; N. Rega; J. M. Millam; M. Klene; J. E. Knox; J. B. 
Cross; V. Bakken; C. Adamo; J. Jaramillo; R. Gomperts; R. E. Stratmann; O. Yazyev; A. J. Austin; R. Cammi; C. Pomelli; J. W. Ochterski; R. L. Martin; K. Morokuma; V. G. Zakrzewski; G. A. Voth; P. Salvador; J. J. Dannenberg; S. Dapprich; A. D. Daniels; Ö. Farkas; J. B. Foresman; J. V. Ortiz; J. Cioslowski; D. J. Fox, Gaussian 09, Revision D.01, Gaussian, Inc., Wallingford, CT, 2009.

[42] Y. Zhao; D. G. Truhlar. Theor. Chem. Acc. 2008, 120, 215-241.

[43] C. Riplinger; F. Neese. J. Chem. Phys. 2013, 138, 034106.

[44] C. Riplinger; B. Sandhoefer; A. Hansen; F. Neese. J. Chem. Phys. 2013, 139, 134101.

[45] D. Datta; S. Kossmann; F. Neese. J. Chem. Phys. 2016, 145, 114101.

[46] F. Weigend; R. Ahlrichs. Phys. Chem. Chem. Phys. 2005, 7, 3297-3305.

[47] J. Zheng; X. Xu; D. G. Truhlar. Theor. Chem. Acc. 2011, 128, 295-305.

[48] F. Neese. Wiley Interdiscip. Rev: Comput. Mol Sci. 2012, 2, 73-78.

[49] F. Neese. Wiley Interdiscip. Rev: Comput. Mol Sci. 2018, 8, e1327.

[50] R. Dennington; T. Keith; J. Millam, Gaussview, Version 4.1, Semichem, Inc., Shawnee Mission, KS (USA), 2000.

[51] G. Cavallo; J. S. Murray; P. Politzer; T. Pilati; M. Ursini; G. Resnati. IUCrJ 2017, 4, 411-419.

[52] Http://Www.Rsc.Org/Periodic-Table/Element/85/Astatine. Accessed: 11 March 2015.

[53] Crc Handbook of Chemistry and Physics; Lide, D. R. (Ed.); 98th ed.; CRC Press: Boca Raton (Fla, USA), 2009.

[54] A. Siiskonen; A. Priimagi. J. Mol. Model. 2017, 23, 50.

[55] F.-Y. Lin; A. D. MacKerell. J. phys. Chem. B 2017, 121, 6813-6821.

[56] Photograph by Christian Ferrer, Distributed under the Creative Commons Attribution-Share Alike 4.0 International License.

\section{Graphical Abstract}

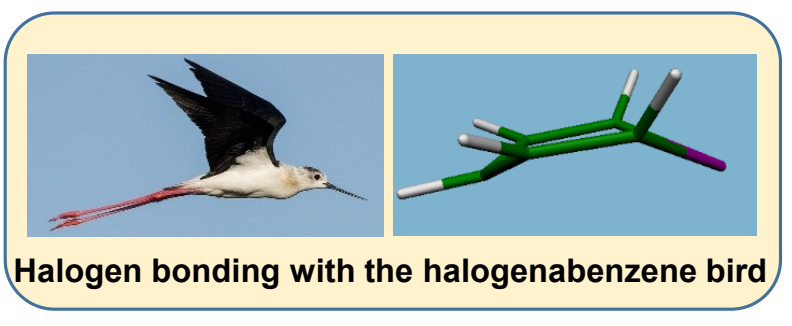

Photograph: Ref ${ }^{[56]}$ 